\title{
Role and Potential of Direct Interspecies Electron Transfer in Anaerobic Digestion
}

\author{
Gahyun Baek, Jaai Kim, Jinsu Kim and Changsoo Lee * \\ School of Urban and Environmental Engineering, Ulsan National Institute of Science and Technology (UNIST), \\ 50 UNIST-gil, Eonyang-eup, Ulju-gun, Ulsan 44919, Korea; baek1625@unist.ac.kr (G.B.); jaai@unist.ac.kr (Ja.K.); \\ penguin0529@unist.ac.kr (Ji.K.) \\ * Correspondence: cslee@unist.ac.kr; Tel.: +82-52-217-2822; Fax: +82-52-217-2819
}

Received: 30 October 2017; Accepted: 28 November 2017; Published: 3 January 2018

\begin{abstract}
Anaerobic digestion (AD) is an effective biological treatment for stabilizing organic compounds in waste/wastewater and in simultaneously producing biogas. However, it is often limited by the slow reaction rates of different microorganisms' syntrophic biological metabolisms. Stable and fast interspecies electron transfer (IET) between volatile fatty acid-oxidizing bacteria and hydrogenotrophic methanogens is crucial for efficient methanogenesis. In this syntrophic interaction, electrons are exchanged via redox mediators such as hydrogen and formate. Recently, direct IET (DIET) has been revealed as an important IET route for AD. Microorganisms undergoing DIET form interspecies electrical connections via membrane-associated cytochromes and conductive pili; thus, redox mediators are not required for electron exchange. This indicates that DIET is more thermodynamically favorable than indirect IET. Recent studies have shown that conductive materials (e.g., iron oxides, activated carbon, biochar, and carbon fibers) can mediate direct electrical connections for DIET. Microorganisms attach to conductive materials' surfaces or vice versa according to particle size, and form conductive biofilms or aggregates. Different conductive materials promote DIET and improve $\mathrm{AD}$ performance in digesters treating different feedstocks, potentially suggesting a new approach to enhancing AD performance. This review discusses the role and potential of DIET in methanogenic systems, especially with conductive materials for promoting DIET.
\end{abstract}

Keywords: anaerobic digestion; conductive material; direct interspecies electron transfer; interspecies electron transfer; methanogenesis

\section{Introduction}

Organic compounds in waste and wastewater are generated from various municipal and industrial sources and can be treated by biological processes. Full-scale wastewater treatment plants use various biological processes, including activated sludge, extended aeration, tricking filter, and anaerobic digestion (AD), to stabilize biodegradable organic compounds via the metabolic activity of aerobic/anaerobic microorganisms [1]. In $\mathrm{AD}$, organic matter is converted into $\mathrm{CO}_{2}$ and $\mathrm{CH}_{4}$ through a series of metabolic reactions of microorganisms. This process affords the advantages of both energy production and wastewater treatment. Typically, biogas obtained from AD has a methane content of $50-60 \%$; biogas with $55 \% \mathrm{CH}_{4}$ content has an upper calorific value of $6.0 \mathrm{KWh} / \mathrm{m}^{3}$ at standard temperatures and pressure (STP) [2]. Furthermore, biogas is environmentally friendly and energy efficient owing to its low emission of hazardous pollutants [3]. Biogas can be used to produce electricity, thereby enabling wastewater treatment plants to achieve energy self-sufficiency. Therefore, studies have tried to improve the overall efficiency and reaction rates of biogas production through changes in operational conditions (e.g., $\mathrm{pH}$, temperature, retention time, etc.), pretreatment methods, biogas upgrading, biostimulation, bioaugmentation, and co-digestion. 
Biological processes primarily depend on the concerted activity of microorganisms involved in a series of microbial steps. Therefore, the key to enhancing AD efficiency is to harmonize and speed-up these activities [4]. Interspecies electron transfer (IET) between syntrophic partners plays an important role in oxidizing higher organic matters and reducing $\mathrm{CO}_{2}$ to $\mathrm{CH}_{4}$ in $\mathrm{AD}$ environments [5]. The balance of this syntrophic relationship provides thermodynamically favorable conditions for the degradation of carboxylic acids, and thus for realizing stable anaerobic digesters. Conventionally, this relationship is balanced by indirect interspecies electron transfer (IIET) using electron carriers like hydrogen and formate. A disruption of this syntrophy can lead to the accumulation of intermediates like volatile fatty acids (VFAs) as well as high hydrogen partial pressure; these can lead to a significant deterioration of AD efficiency [6].

Recently, direct interspecies electron transfer (DIET) in AD environments has been suggested as an alternative to IIET. DIET is energetically more advantageous because it does not need hydrogen to be produced for use as an electron carrier [7]. Summers et al. [8] first reported DIET in co-cultures of Geobacter metallireducens and Geobacter sulfurreducens. They observed that DIET can be realized between different species through biological electrical connections by using the multiheme c-type cytochrome OmcS and electrically conductive pili [9]. Subsequently, Kato et al. [10] suggested that cell-to-cell electron transfer can also be mediated through nonbiological conductive materials. In this study, magnetite $\left(\mathrm{Fe}_{3} \mathrm{O}_{4}\right)$, a conductive iron oxide, was used to promote extracellular electron transfer. We demonstrated that its use enhanced organic degradation and methanogenesis rates. Several other conductive materials, such as granular activated carbon (GAC), biochar, and carbon cloth, have also been reported to promote DIET in mixed cultures and defined co-cultures [6,11-14].

Although the specific characteristics of different types of conductive materials vary, all show similar behavior with regards to facilitating DIET in AD. This suggests the potential for establishing a relatively simple method to improve the efficiency and rate of AD by using conductive materials as promoters. Therefore, many studies have recently focused on the mechanisms of DIET and its impact on anaerobic biotechnology $[7,15-17]$. This review discusses the role and significance of DIET in the $\mathrm{AD}$ process and summarizes recent findings on its mechanisms and potential applications.

\section{Indirect Interspecies Electron Transfer}

In methanogenic environments, the syntrophic association between hydrogen-producing bacteria and hydrogen-consuming methanogens is the key to maintaining balanced and stable conditions. The slow syntrophic metabolism of propionate and butyrate in anaerobic digesters has often been reported as a crucial limiting factor for the overall reaction rate [18]. IIET via hydrogen and formate as electron carriers is known as a major pathway for electron exchange between syntrophic microorganisms. The anaerobic degradation of major intermediates of $\mathrm{AD}$, such as propionate and butyrate, is thermodynamically unfavorable (i.e., endergonic reaction under standard conditions) without a scavenging reaction (Table 1). Hydrogen or formate as a reducing equivalent should be consumed rapidly by methanogens for the growth and metabolism of syntrophs; in other words, the reaction is enabled by low hydrogen partial pressure or formate concentration. Therefore, many studies have attempted to provide favorable conditions for syntrophic communities in anaerobic digesters. For example, intermicrobial distances can be shortened by producing compact aggregates or by providing proper mixing conditions [18-20]. Besides this, mixing is an important factor that determines, for example, the distribution of input flow and the development of flocs and aggregates. This section discusses the mechanisms and microbial metabolisms of interspecies hydrogen transfer (IHT) and interspecies formate transfer (IFT) as well as their limitations. 
Table 1. Major reactions of syntrophic metabolisms via interspecies hydrogen/formate transfer and their Gibbs free energy $\left(\Delta \mathrm{G}^{\circ \prime}\right)$ at $\mathrm{pH} 7$.

\begin{tabular}{|c|c|c|c|}
\hline Electron Carrier & Major Reactions & Reactions & $\Delta \mathrm{G}^{\circ \prime}(\mathrm{kJ} / \mathrm{mol})$ \\
\hline Hydrogen & $\begin{array}{l}\text { Propionate degradation } \\
\text { Methane production } \\
\text { Overall reaction } \\
\text { Butyrate degradation } \\
\text { Methane production } \\
\text { Overall reaction }\end{array}$ & $\begin{array}{c}\text { Propionate }{ }^{-}+3 \mathrm{H}_{2} \mathrm{O} \rightarrow \text { Acetate }^{-}+\mathrm{HCO}_{3}{ }^{-}+\mathrm{H}^{+}+3 \mathrm{H}_{2} \\
3 / 4 \mathrm{HCO}_{3}-+3 / 4 \mathrm{H}^{+}+3 \mathrm{H}_{2} \rightarrow 3 / 4 \mathrm{CH}_{4}+9 / 4 \mathrm{H}_{2} \mathrm{O} \\
\text { Propionate }^{-}+3 / 4 \mathrm{H}_{2} \mathrm{O} \rightarrow \mathrm{Acetate}^{-}+1 / 4 \mathrm{HCO}_{3}{ }^{-}+1 / 4 \mathrm{H}^{+}+3 / 4 \mathrm{CH}_{4} \\
\text { Butyrate }+2 \mathrm{H}_{2} \mathrm{O} \rightarrow 2 \text { Acetate }^{-}+\mathrm{H}^{+}+2 \mathrm{H}_{2} \\
1 / 2 \mathrm{HCO}_{3}{ }^{-}+1 / 2 \mathrm{H}^{+}+2 \mathrm{H}_{2} \rightarrow 1 / 2 \mathrm{CH}_{4}+3 / 2 \mathrm{H}_{2} \mathrm{O} \\
\text { Butyrate }^{-}+1 / 2 \mathrm{H}_{2} \mathrm{O}+1 / 2 \mathrm{HCO}_{3}^{-} \rightarrow 2 \text { Acetate }^{-}+1 / 2 \mathrm{H}^{+}+1 / 2 \mathrm{CH}_{4}\end{array}$ & $\begin{array}{l}+76.5 \\
-101.7 \\
-25.2 \\
+48.3 \\
-67.8 \\
-19.5\end{array}$ \\
\hline Formate & $\begin{array}{l}\text { Propionate degradation } \\
\text { Methane production } \\
\text { Overall reaction } \\
\text { Butyrate degradation } \\
\text { Methane production } \\
\text { Overall reaction }\end{array}$ & $\begin{array}{c}\text { Propionate }^{-}+2 \mathrm{H}_{2} \mathrm{O}+2 \mathrm{CO}_{2} \rightarrow \text { Acetate }^{-}+3 \mathrm{HCOO}^{-}+\mathrm{H}^{+} \\
3 \mathrm{HCOO}^{-}+3 \mathrm{H}^{+} \rightarrow 3 / 4 \mathrm{CH}_{4}+9 / 4 \mathrm{CO}_{2}+3 / 2 \mathrm{H}_{2} \mathrm{O} \\
\text { Propionate }^{-}+2 \mathrm{H}^{+}+1 / 2 \mathrm{H}_{2} \mathrm{O} \rightarrow \text { Acetate }^{-}+1 / 4 \mathrm{CO}_{2}+3 / 4 \mathrm{CH}_{4} \\
\text { Butyrate }^{-}+2 \mathrm{H}_{2} \mathrm{O}+2 \mathrm{CO}_{2} \rightarrow 2 \text { Acetate }^{-}+2 \mathrm{HCOO}^{-}+2 \mathrm{H}^{+} \\
2 \mathrm{HCOO}^{-}+2 \mathrm{H}^{+} \rightarrow 1 / 2 \mathrm{CH}_{4}+3 / 2 \mathrm{CO}_{2}+\mathrm{H}_{2} \mathrm{O} \\
\text { Butyrate }^{-}+\mathrm{H}_{2} \mathrm{O}+1 / 2 \mathrm{CO}_{2} \rightarrow 2 \text { Acetate }^{-}+1 / 2 \mathrm{CH}_{4}\end{array}$ & $\begin{array}{l}+65.3 \\
-144.5 \\
-79.2 \\
+38.5 \\
-96.3 \\
-57.8\end{array}$ \\
\hline
\end{tabular}

\subsection{Interspecies Hydrogen Transfer}

The conversion of complex organic compounds into methane via AD proceeds through several microbial steps: hydrolysis, acidogenesis, acetogenesis, and methanogenesis. These steps are respectively performed by four major functionally different microbial groups: hydrolytic bacteria, acidogenic bacteria, syntrophic acetogenic bacteria, and methanogenic archaea. First, complex organic compounds are broken down by hydrolytic bacteria into smaller molecules. Acidogenic bacteria ferment these hydrolytic products to organic acids and alcohols, including VFAs and ethanol, with hydrogen being produced as a byproduct [21]. Acetogenic bacteria further oxidize more-reduced intermediates, such as lactate, ethanol, propionate, and butyrate, to acetate. Acetate is then converted into $\mathrm{CO}_{2}$ and $\mathrm{CH}_{4}$ by methanogens. Acetogenesis and methanogenesis should together constitute a healthy syntrophic relationship because acetogenesis is an endergonic reaction. It is important to ensure that hydrogen, an acetogenic product, is effectively removed by hydrogen consumers, especially methanogens, because high hydrogen partial pressure inhibits the regeneration of the cytoplasmic pool of oxidized coenzymes in acetogenic bacteria [22]. Syntrophic hydrogen consumption by methanogens helps keep the overall reaction exergonic (Table 1). Controlling the hydrogen concentration is crucial for realizing stable and effective AD.

Molecular hydrogen is a minor component in the environment; however, it plays an important role in $\mathrm{AD}$ metabolism as a convenient vehicle for electron transport between different organisms [18,23]. In sediments dominated by methanogenesis as a terminal electron-accepting step, hydrogen is an intermediate for $\sim 40 \%$ of the electron flow [24]. Microorganisms that catalyze the hydrogen metabolism contain the key enzyme hydrogenase. Hydrogen can be consumed or produced by this metalloenzyme that catalyzes the reversible heterolytic cleavage of molecular hydrogen [25]. Figure 1 shows the intracellular redox mediators for hydrogen production and consumption. Microorganisms that contain hydrogenases reduce protons through the oxidation of reduced ferredoxin, NADH, and $\mathrm{FADH}_{2}$ [26]. The oxidation reactions of reduced ferredoxin and NADH are energetically favorable when methanogens keep the hydrogen partial pressure low enough, while the oxidation reaction of $\mathrm{FADH}_{2}$ needs ATP to be feasible [27]. Most known methanogens are hydrogenotrophic methanogens that gain energy from the reduction of $\mathrm{CO}_{2}$ to $\mathrm{CH}_{4}$ by using hydrogen as an electron donor. Coenzyme $\mathrm{F}_{420}$ and oxidized ferredoxin are reduced by hydrogen-uptake hydrogenase as electron carriers, as shown in Figure 1 [28]. Reduced ferredoxin $\left(\mathrm{Fd}_{(\mathrm{red})}\right)$ and reduced $\mathrm{F}_{420}\left(\mathrm{~F}_{420}-\mathrm{H}_{2}\right)$ act as direct electron donors through successive steps from $\mathrm{CO}_{2}$ to formyl, methylene, and methyl levels. 


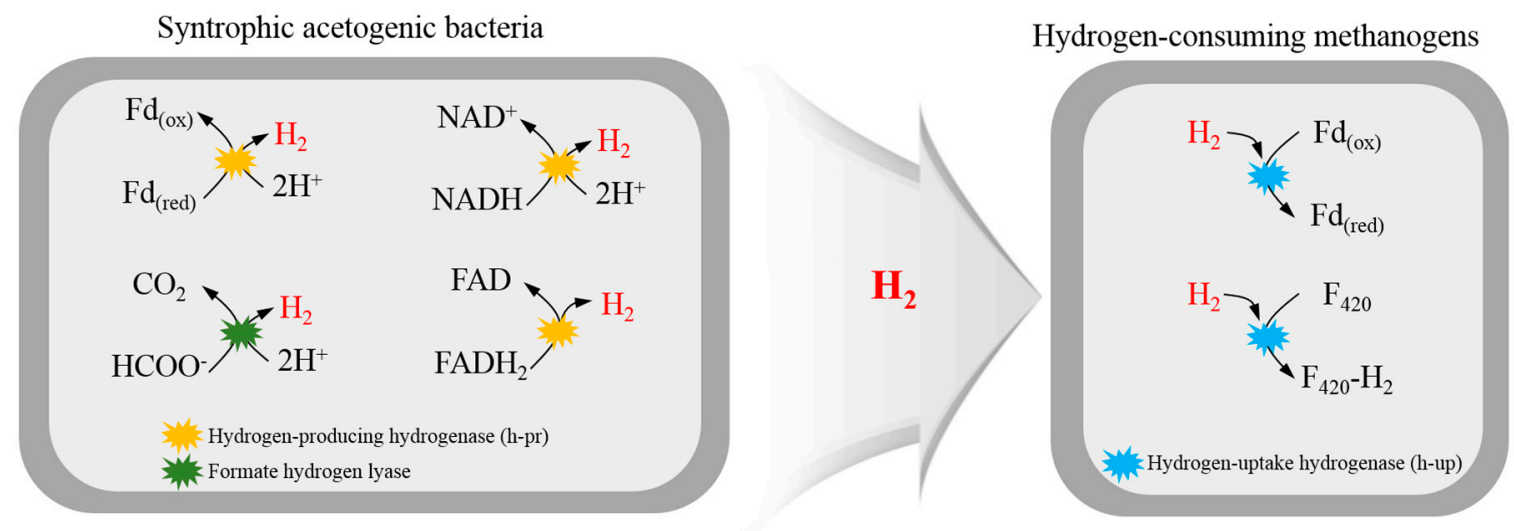

Figure 1. Interspecies hydrogen transfer and intracellular redox mediators for hydrogen consumption and production.

\subsection{Interspecies Formate Transfer}

Most hydrogenotrophic methanogens can use formate as well as hydrogen as major electron donors. Formate is oxidized to $\mathrm{CO}_{2}$ by formate dehydrogenase (Fdh), following which $\mathrm{CO}_{2}$ is reduced to methane [29]. Although most studies focus on IHT in syntrophic methanogenesis, IFT can sometimes function as a major route for electron transfer. For example, Boone et al. [30] reported that formate diffusion accounted for 98-fold more IET than hydrogen diffusion. Furthermore, Thiele and Zeikus [22] observed that IFT was a major IET mechanism, whereas hydrogen was an insignificant intermediate in syntrophic ethanol-degrading flocs from an anaerobic digester treating whey. These studies demonstrated the significance of formate as a diffusive redox mediator in methanogenic cultures.

Hydrogen and formate function similarly in mediating electrons for IIET in AD processes; however, they have different physicochemical characteristics. Hydrogen has an advantage over formate in generating a concentration gradient because of its much lower solubility. This difference makes the concentration gradient between producing and scavenging microorganisms significantly higher (up to 1000-fold) with hydrogen than with formate [31]. On the other hand, hydrogen shows a 30-fold higher diffusion rate in water compared to formate. Because of these different characteristics, IFT can be superior to IHT when the intermicrobial distances are large, and vice versa, in terms of generating a concentration gradient.

\section{Direct Interspecies Electron Transfer}

DIET has recently been identified as an important mechanism for IET between syntrophic microorganisms involved in the anaerobic degradation of VFAs in AD. In DIET communities, electrons released from exoelectrogenic microorganisms are directly transferred to electron-capturing microorganisms via membrane-associated cytochromes and conductive pili that form electrical connections between syntrophic partners. DIET could alternatively be mediated by abiotic conductive materials in methanogenic cultures. DIET has been suggested to be faster and energetically more efficient than IIET via hydrogen or formate as electron carriers; therefore, methanogenic performance can potentially be enhanced by promoting DIET in AD [32]. In this section, the fundamentals and mechanisms of DIET are briefly discussed based on observations in defined co-culture studies.

\subsection{Comparison between DIET and IIET}

The main limitation of the IIET mechanism is that any stagnation in this process causes the accumulation of VFAs, and high VFA concentrations (especially for propionate) are toxic to methanogens. The syntrophic association between acetogenesis and methanogenesis is often considered the rate-limiting step of the overall AD process [33]. Therefore, under high organic loading conditions, fast growth of acidogenic bacteria can lead to excessive accumulation of VFAs 
and hydrogen to levels that cannot be effectively handled by slow-growing methanogens and VFA degraders. This results in fast accumulation of excess fermentation products, in turn leading to unfavorable conditions for methanogens [34]. On the contrary, DIET has an advantage over IIET from a thermodynamic viewpoint because DIET does not need complex enzymatic steps to produce, consume, and diffuse the redox mediators (Figure 2A,B). For example, in the case of propionate oxidation by propionate-oxidizing bacteria (POB), the standard Gibbs free energy of IHT and DIET can be represented as Equations (1) and (2), respectively [35].

$$
\begin{gathered}
\mathrm{C}_{2} \mathrm{H}_{5} \mathrm{COO}^{-}+3 \mathrm{H}_{2} \mathrm{O} \rightarrow \mathrm{CH}_{3} \mathrm{COO}^{-}+\mathrm{HCO}_{3}{ }^{-}+\mathrm{H}^{+}+3 \mathrm{H}_{2} \\
\Delta \mathrm{G}^{\mathrm{o}^{\prime}}=72.7 \mathrm{~kJ} / \mathrm{mol}\left(37^{\circ} \mathrm{C}, \mathrm{pH} 7\right) \\
\mathrm{C}_{2} \mathrm{H}_{5} \mathrm{COO}^{-}+0.75 \mathrm{H}_{2} \mathrm{O} \rightarrow \mathrm{CH}_{3} \mathrm{COO}^{-}+0.25 \mathrm{HCO}_{3}{ }^{-}+0.25 \mathrm{H}^{+}+0.75 \mathrm{CH}_{4} \\
\Delta \mathrm{G}^{0^{\prime}}=-26.4 \mathrm{~kJ} / \mathrm{mol}\left(37^{\circ} \mathrm{C}, \mathrm{pH} 7\right)
\end{gathered}
$$
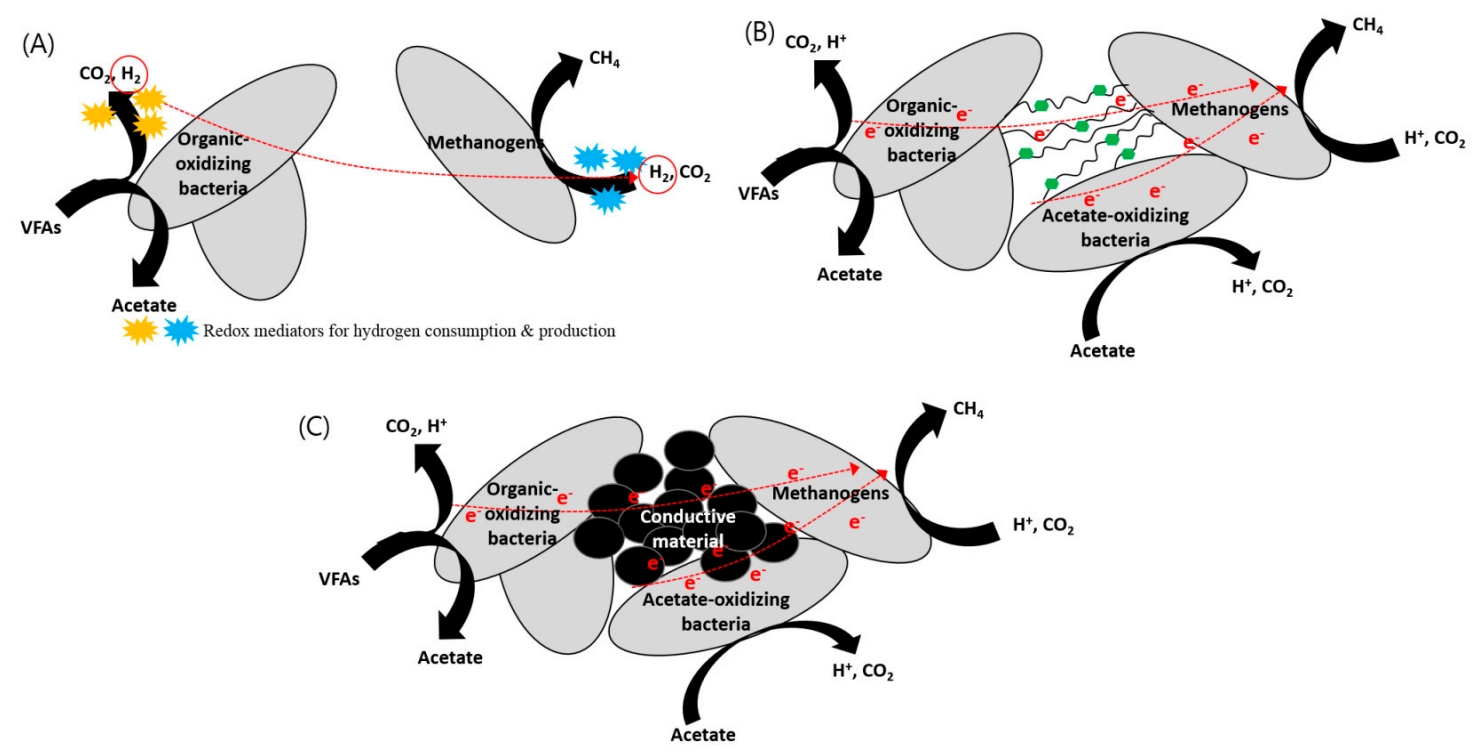

Figure 2. Mechanisms of (A) indirect interspecies electron transfer (IIET) via hydrogen, (B) biological direct interspecies electron transfer (DIET), and (C) conductive material-mediated DIET.

As seen in the above equations, the oxidative half-reaction of propionate degradation is thermodynamically not a favorable reaction, whereas methane is produced directly from $\mathrm{H}^{+}, \mathrm{e}^{-}$, and $\mathrm{CO}_{2}$ via DIET. Furthermore, DIET is more energy-efficient than IHT, which loses energy owing to the formation and consumption of intermediates [32]. In IHT, the methanogenic reaction must be followed to keep lower $\mathrm{H}_{2}$ concentration and negative Gibbs free energy to yield energy (Table 1). Jing et al. [35] calculated the Gibbs free energy value during the batch experiment under DIET-stimulated conditions and found that it was more negative for DIET than for IHT. They stated that higher propionate degradation rates could be achieved owing to the promotion of DIET. Furthermore, a recent study revealed that DIET showed even higher external electron transfer rates than hydrogen-based IET $\left(44.9 \times 10^{3}\right.$ and $5.24 \times 10^{3} \mathrm{e}^{-} /$cell pair/s for DIET and IHT, respectively) [36]. These authors reported that the main limiting factor for conventional IET is the mediator concentration gradient, whereas that for DIET is activation losses (overpotentials) when electrons are transferred between membrane-associated cytochromes and microbial nanowires. 


\subsection{DIET Mechanisms}

Extracellular electron transfer reportedly occurs through three different mechanisms: (1) soluble redox shuttles, (2) direct contact between the electron acceptor and the redox-active protein on the outer-membrane surface, or (3) conductive filamentous structures [37]. Biological DIET includes the second and third mechanisms in the form of cell-to-cell electron transfer via biological components like c-type cytochromes and conductive pili.

The c-type cytochrome is essential to the electron transfer mechanism of microbial species by undergoing oxidation and reduction. Most well-known exoelectrogenic microorganisms, such as Geobacter and Shewanella, are known to be capable of transporting electrons through a chain of cytochrome c toward extracellular electron acceptors [38]. They use cytochrome c to donate electrons to solid-state electron acceptors such as electrodes in bioelectrochemical systems, insoluble chemical electron acceptors (iron oxides, sulfate, and nitrate), and soluble redox compounds (humic compounds or riboflavin). In Shewanella oneidensis MR-1, a well-known metal-reducing bacterium, c-type cytochromes (OmcA, MtrC, and CymA) play a role in transporting electrons from the quinone/quinol pool of the inner membrane, to the periplasm, to the outer membrane, and finally to extracellular electron acceptors like metal oxides [39]. G. sulfurreducens also contains c-type cytochromes (OmcS and OmcE); however, its conceptual model is quite different from that of S. oneidensis MR-1. Leang et al. [37] reported a close association between OmcS and conductive pili in G. sulfurreducens by suggesting a mechanism in which OmcS facilitates electron transfer from pili to ferric oxides. This model proposes that electron conduction is achieved through the conductive pili; however, OmcS should play a role in transferring electrons from pili to ferric oxides.

Another DIET mechanism, called microbial nanowires, also uses conductive pili. Conductive pili have been observed in many studies by atomic force microscopy (AFM), scanning electron microscopy (SEM), scanning tunneling microscopy (STM), and transmission electron microscopy (TEM) [8,40-42]. Conductive pili are protein filaments produced by microorganisms for long-range electron transfer under suitable conditions [43]. Through pili, longer-range electron transfer can occur without a direct contact mechanism to insoluble minerals, solid electrodes, other microorganisms, and even electrically conductive biofilm [44]. Two mechanisms have been proposed for how pili show electrical conductivity. The first mechanism is metal-like conduction in which charges are spread across the entire filament. This can occur through pi-pi orbital overlaps and charge delocalization, as has been observed frequently in many conductive organic materials [45]. Metallic-like conductivity in biological proteins was first reported with G. sulfurreducens pili; these show electronic conductivity of $\sim 5 \mathrm{mS} / \mathrm{cm}$, which is comparable to that of synthesized metallic nanotubes. The second mechanism is an electron hopping/tunneling mechanism in which electrons can move by hopping or tunneling through pili. In this mechanism, electrons jump from cytochrome to cytochrome; therefore, the involvement of cytochromes is a crucial factor. However, Malvankar et al. [43] found evidence of the irrelevance of cytochromes and electron transport in conductive G. sulfurreducens biofilms. AFM images showed that cytochromes were not located close enough on pili to enable the hopping or tunneling of electrons. Furthermore, the inactivation of cytochromes did not have any negative effect on biofilm conductivity. Thus, the authors reported that long-range electron transfer through nanowires in G. sulfurreducens is based on metallic-like filaments rather than on a hopping or tunneling mechanism between c-type cytochromes. On the other hand, Pirbadian et al. [46] reported that the conductive pili of S. oneidensis are an extension of the outer membrane and periplasm, which include multiheme cytochromes responsible for electron transport. They proposed that $S$. oneidensis conducts electrons through a multistep cytochrome-to-cytochrome electron hopping/tunneling mechanism.

\subsection{First Observations of Biological DIET in Anaerobic Cultures}

The DIET mechanism was first observed in defined co-cultures of G. metallireducens and G. sulfurreducens [8]. In the co-culture medium, ethanol and fumarate were the sole electron donor and acceptor, respectively, and they need to share electrons because G. metallireducens cannot use fumarate 
as an electron acceptor whereas G. sulfurreducens cannot oxidize ethanol. The authors observed that the co-culture oxidized ethanol through the formation of tight and electrically conductive aggregates. The deletion of the genes encoding the hydrogenase subunit did not affect the ethanol metabolism, and the abundance of genes for cytochrome OmcS and pili was closely correlated with the syntrophic co-culture. They concluded that DIET, and not IET via hydrogen or formate as electron carriers, was the predominant electron transfer mechanism under selective pressure for effective electron transfer. After this observation, similar experimental results demonstrating DIET under certain conditions were reported in defined co-cultures (Table 2).

Table 2. Observational and experimental evidence for biological direct interspecies electron transfer (DIET) in defined co-cultures.

\begin{tabular}{|c|c|c|c|}
\hline $\begin{array}{l}\text { Electron-Donating } \\
\text { Microorganism }\end{array}$ & $\begin{array}{l}\text { Electron-Accepting } \\
\text { Microorganism }\end{array}$ & Evidence & Reference \\
\hline $\begin{array}{c}\text { Geobacter } \\
\text { metallireducens }\end{array}$ & $\begin{array}{c}\text { Geobacter } \\
\text { sulfurreducens }\end{array}$ & 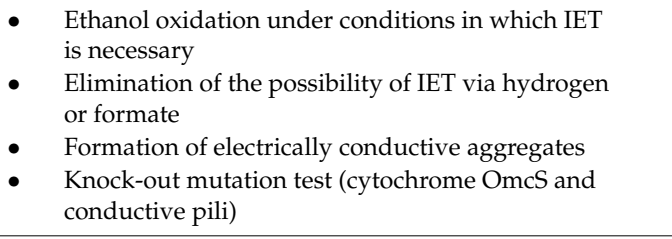 & Summers et al., 2010 \\
\hline $\begin{array}{c}\text { Geobacter } \\
\text { metallireducens }\end{array}$ & Methanosarcina barkeri & $\begin{array}{l}\text { - } \\
\text { is necessary } \\
\text { - } \quad \text { Formation of close aggregates } \\
\text { - } \quad \text { Knock-out mutation test (conductive pili) }\end{array}$ & Rotaru et al., 2014a \\
\hline $\begin{array}{c}\text { Geobacter } \\
\text { metallireducens }\end{array}$ & $\begin{array}{l}\text { Methanosaeta } \\
\text { harundinacea }\end{array}$ & $\begin{array}{l}\text { - } \quad \text { Formation of close aggregates } \\
\text { - } \quad \text { Lack of the ability of G. metallireducens to grow via IHT } \\
\text { - } \quad \text { Transcriptomic analysis } \\
\text { - } \quad \text { Knock-out mutation test (c-type cytochrome and } \\
\text { conductive pili) } \\
\text { - } \quad \text { Isotopic labeling using }{ }^{14} \mathrm{CO}_{2}\end{array}$ & Rotaru et al., 2014b \\
\hline
\end{tabular}

Rotaru et al. [47] were the first to prove the ability of methanogens (Methanosarcina barkeri) to participate in DIET in a G. metallireducens co-culture. They presented evidence similar to that of the first experimental study conducted by Summers et al. [8], in which two species must give and take electrons for the metabolism of ethanol to methane. The experimental results strongly suggested that the direct use of electrons by M. barkeri occurred as shown in Equation (3), rather than by conventional hydrogenotrophic methanogenesis.

$$
8 \mathrm{H}^{+}+8 \mathrm{e}^{-}+\mathrm{CO}_{2} \rightarrow \mathrm{CH}_{4}+2 \mathrm{H}_{2} \mathrm{O}
$$

Similar ability of DIET-mediated methanogenesis was observed in Methanosaeta harundinaceae. The Methanosaeta species is generally known to be able to utilize acetate only as substrate; however, it cannot convert hydrogen or formate to methane. Rotaru et al. [38] observed that the methanogenic aggregates collected from an anaerobic digester treating brewery wastewater were highly dominated by Methanosaeta species (over 90\%) and capable of efficiently converting ethanol to methane. Given that Methanosaeta cannot use hydrogen or formate for the electron donor, IIET cannot be the primary IET mechanism necessary for the syntrophic oxidation of ethanol for methanogenesis in the aggregates. Furthermore, these aggregates showed electrically conductive characteristics, and Geobacter species were the predominant bacterial group (approximately $25 \%$ of the bacterial $16 \mathrm{~S}$ rRNA sequences were recovered as Geobacter species). Based on these observations, the authors speculated that DIET was the primary mechanism for electron exchange within these aggregates. A significant volume of evidence was presented to support their speculation. Transcriptomic analysis revealed a highly abundant and complete complement of genes for the reduction of $\mathrm{CO}_{2}$ to $\mathrm{CH}_{4}$ in M. harundinaceae. Furthermore, highly expressed genes for ethanol metabolism and production of conductive pili were detected in G. metallireducens. The authors confirmed that there was no methane production from 
ethanol oxidation in co-cultures of G. metallireducens with $\mathrm{H}_{2}$ - and formate-utilizing methanogens. This result excluded the possibility of IIET via $\mathrm{H}_{2}$ or formate. Furthermore, radiotracer, stoichiometric modeling, and mutant strain experiments suggest that Methanosaeta species can participate in DIET. This interesting discovery suggests that Methanosaeta plays an important role in directly accepting electrons from other species as well as in acetate metabolism.

\section{Conductive Materials to Promote DIET}

As discussed in Section 3, DIET usually involves biological electrical connections (i.e., cytochrome or pili) between microorganisms. However, DIET can also occur through conductive materials as nonbiological electric conduits, as shown in Figure 2C [11]. Under a conductive-material-supplemented environment, microorganisms do not form tight aggregates of the kind that are necessary for direct physical contact or electrical connection through pili between cells; instead, they seem to be tightly attached to the surface of the conductive materials $[11,12,14]$ (Figure 3). Furthermore, important biological tools for DIET, such as pili and cytochrome OmcS, are not required for electron exchange if conductive materials exist. Recently, DIET stimulation by the supplementation of conductive materials has been studied in engineered systems such as lab-scale anaerobic digesters as well as co-cultures. Most bioreactors are inoculated using an undefined mixed culture that has a much more complex microbial community structure than a defined co-culture. They may behave differently in response to different conductive materials, and this is an important point to address for practical applications. The following subsections discuss the use of different types of conductive materials to promote DIET and their effects on metabolic activities, particularly in methanogenic cultures.

(A)

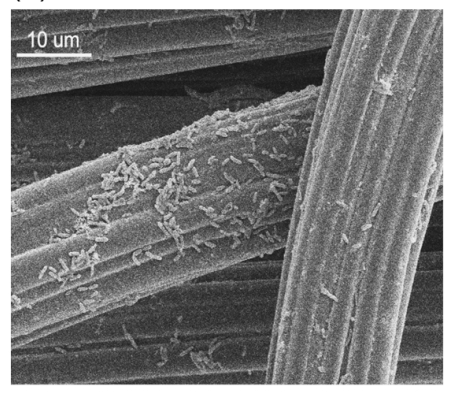

(B)

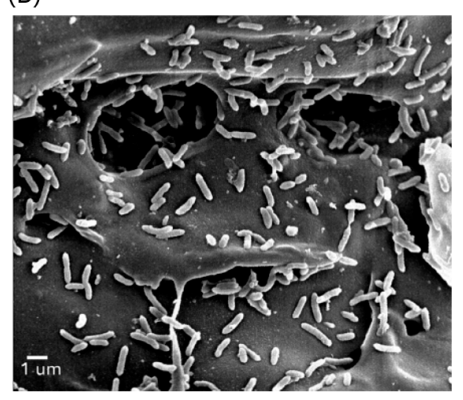

(C)

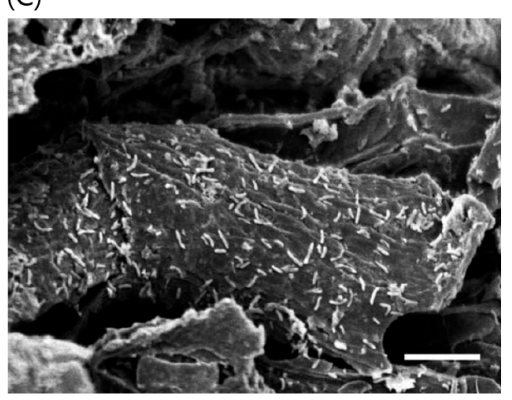

Figure 3. Physical contact between conductive materials and microorganisms for (A) carbon cloth (adapted from Chen et al. [11]), (B) biochar (adapted from Chen et al. [12]), and (C) activated carbon (adapted from Liu et al. [14]).

\subsection{Iron Oxides}

Iron oxides on Earth are known to play an important role in biological and geological reactions. Given that there are different types of iron oxide particles with different conductivities, such as insulative (ferrihydrite), semiconductive (hematite and goethite), and conductive (magnetite), they are suitable for use in experiments to test whether the DIET mechanism is stimulated by conductive materials. Kato and Watanabe [33] first explored the use of this characteristic (i.e., different conductivities of different types of iron oxides) to observe interactions in soil bacteria, and they found that nanosized iron oxide particles can facilitate the respiratory mechanism of soil microbial cultures. Kato et al. [10] further confirmed that the conductivity of iron oxides can determine the methanogenesis rate from enriched microbial communities from rice paddy soils. In this study, three different iron oxides with different conductivities (magnetite, hematite, and ferrihydrite) were investigated. It was found that (semi)conductive iron oxides could facilitate methanogenesis from acetate and ethanol, with improvements in both lag time and production rate. Any other effect of ferrous ions, including acting as a nutrient or electron shuttle, was excluded upon the detection of an extremely small amount of ferrous ions under 
hematite- and magnetite-supplemented conditions. This explained the enhanced methanogenesis with the establishment of an electrical syntrophic relationship between Geobacter and Methanosarcina via (semi)conductive iron oxides. This hypothesis was supported by real-time PCR results in the presence and absence of methanogenesis inhibitors. The abundance of Geobacter was not dependent on the presence of an inhibitor in the ferrihydrite-supplemented conditions, but was strongly affected in hematite- and magnetite-supplemented conditions. The results suggest that the Geobacter used (semi)conductive iron oxides as electron conduits towards Methanosarcina, making them candidates for syntrophic partnership (Figure 4).

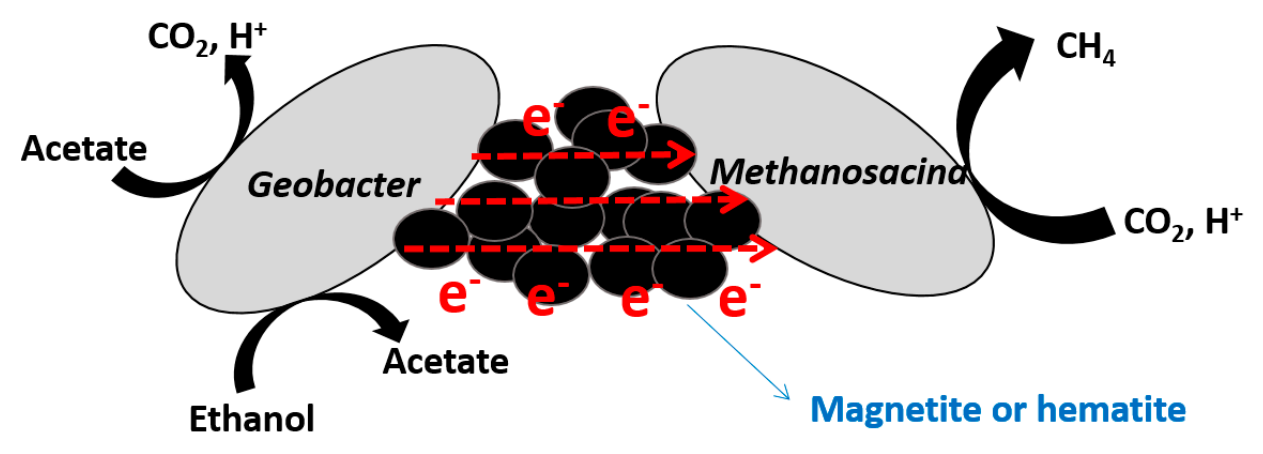

Figure 4. Schematic of suggested mechanisms under hematite- and magnetite-supplemented conditions.

Since Kato and Watanabe's [33] study, magnetite has attracted much attention as a promoter for DIET. It is the main component of iron ores on Earth, and it has conductive and ferrimagnetic characteristics. Among all naturally occurring minerals on Earth, it is the most magnetic and is harmless to the environment and to living things. Therefore, it has attracted interest in various application fields including drug delivery, contrast agents for magnetic resonance imaging, immunoassays, and molecular biotechnology [48,49]. Furthermore, magnetite can be synthesized easily by the addition of stoichiometric amounts of $\mathrm{Fe}^{2+}$ and $\mathrm{Fe}^{3+}$ in ammonia, and basic solution and size control is possible; this suggests its various potential applications [50]. The most important characteristic of magnetite as a promoter for DIET is its conductivity. The electrical conductivity and resistivity of magnetite are $2.5 \times 10^{2} \Omega \cdot \mathrm{cm}^{-2}$ and $0.000005 \mathrm{M} \Omega \cdot \mathrm{cm}$, respectively (electrical resistivity values of hematite and goethite are 2 and $16 \mathrm{M} \Omega \cdot \mathrm{cm}$, respectively) [51].

Kato et al. [52] investigated the possibility of DIET in co-cultures of G. sulfurreducens and Thiobacillus denitrificans when stimulating DIET by supplementation with magnetite and not by a naturally formed biological electrical connection. As in other experiments with defined co-cultures (Section 3), G. sulfurreducens can oxidize acetate but cannot reduce nitrate; the opposite is true for T. denitrificans. The authors could not observe any reaction (i.e., oxidation of acetate or reduction of nitrate) in the co-culture of the two species, suggesting that electron exchange via direct biological electrical connections like pili or cytochromes is not possible between them. IIET mediated by $\mathrm{H}_{2}$ or formate also cannot occur in this environment because T. denitrificans is not capable of using these electron carriers as electron donors. However, supplementation with semiconductive and conductive iron oxides induced the reaction, where magnetite stimulated a much faster electron transfer. The electron transfer curve, X-ray diffraction (XRD) spectra pattern, and SEM images supported the possibility of DIET between two species via electric currents through conductive magnetite.

Thereafter, magnetite addition to stimulate DIET has been studied in various substrates in mixed cultures. Cruz Viggi et al. [53] first reported the effect of magnetite addition to facilitate the degradation of propionate, a central intermediate in $\mathrm{AD}$ with rice paddy soil as an inoculum. Indeed, the addition of micrometer-sized $(100-150 \mathrm{~nm})$ magnetite triggered a methane production rate that was $33 \%$ higher than that of a control reactor; they proposed that this stimulatory effect was derived from the DIET mechanism with magnetite particles acting as an electron conduit between microorganisms. Similarly, Li et al. [54] reported the improvement of butyrate degradation by magnetite supplementation in 
paddy soil enrichments. They used nanosized $(30 \mathrm{~nm})$ magnetite particles to accelerate the methane production rate in the whole subculture enrichment. The addition of anthraquinone-2-sulfonate (AQS), which acted as an electron shuttle outside the cells, did not facilitate methane production, and the stimulatory effect of magnetite disappeared completely when it was insulated by a silica coating. Both observations suggested that the electrical conductivity of magnetite particles is the key to enhanced methanogenesis. Yamada et al. [55] tested the effect of magnetite addition under thermophilic conditions, unlike other studies that were conducted in a mesophilic environment. Observations of the putative electric syntrophy between VFA-oxidizing bacteria and Methanosarcina species suggested that faster degradations of acetate and propionate occurred successfully even under thermophilic conditions. Mixed VFAs containing an equimolar mixture of acetate, propionate, butyrate, valerate, and caprotate were used as an artificial substrate for the methanogenic test with magnetite supplementation [56]. The degradation rate of C2-C6 VFAs was improved significantly by magnetite addition, and this effect was particularly pronounced for longer-chain VFAs. Zhuang et al. [57] used benzoate, an intermediate in the methanogenesis of aromatic compounds, as a substrate; its degradation rates were increased remarkably in the presence of hematite $(25 \%)$ and magnetite $(53 \%)$ compared to a control.

This positive effect on biomethanation was further confirmed in real wastewaters produced from different sources. Baek et al. [58] compared the AD performances of reactors under conductive-magnetiteand semiconductive-goethite-supplemented conditions with that of a control reactor without iron oxide. Batch experiments were conducted to treat cheese whey, a high-strength organic wastewater produced in cheese manufacturing, with a mixed culture as an inoculum. Much faster organic removal and methane production were observed, with corresponding producing and consuming patterns of intermediates (i.e., VFAs and hydrogen). The effect of magnetite addition to treat cheese whey was further investigated in the continuous mode to focus more on the process performance and stability over a long-term period (over 360 days) [6]. The reactor with added magnetite showed much better performance for both methane production and organic degradation. Furthermore, it was more resistant to process imbalances. By contrast, the control reactor showed significant process imbalance, especially with the accumulation of propionic acid. In both experiments (i.e., batch and continuous tests), Methanosaeta species accounted for a major proportion of the archaeal community structure in magnetite-supplemented environments. As discussed in Section 3, Methanosaeta can participate in DIET by directly accepting electrons and reducing $\mathrm{CO}_{2}$ to $\mathrm{CH}_{4}$ [38]; thus, the authors suggested that Methanosaeta are likely responsible for biomethanation by aceticlastic as well as DIET-mediated pathways.

Apart from conductivity, the addition of magnetite also affords the advantage of strong magnetism. Baek et al. [59] exploited magnetism to minimize magnetite consumption from the viewpoint of economic feasibility while maintaining the improved DIET-mediated biomethanation performance. The authors tried to capture magnetite particles from the effluent by using neodymium magnets and then recycled them by mixing them with the influent. This novel strategy was successfully tested over a long period ( $>250$ days) without adding extra magnetite particles, and it even helped to retain more biomass inside the reactors via the self-aggregation of magnetite-microorganism complexes.

\subsection{Biochar and Activated Carbon}

Biochar, which is produced by the thermochemical conversion of biomass, is a carbon-rich and biostable material used as a soil amendment to enhance soil quality [60]. Usually, biochar has a high internal surface area due to its porous structure, which provides a favorable environment for soluble organic matter, gases, and nutrients to diffuse inside [61]. Thus, it can provide matrices for adhesion and attachment of microorganisms and reduce inhibition by absorbing possible inhibitors in anaerobic digesters [62]. Activated carbon has high porosity and adsorptive properties as a result of physical and chemical activation processes [63]. Similar to biochar, activated carbon has been reported to enhance thermophilic methanogenesis from swine manure by adsorption of sulfides, which can inhibit AD [64]. 
Therefore, the application of biochar and activated carbon to AD has focused largely on removing inhibitors by adsorption and promoting the attached growth of microorganisms.

However, recently, it has been revealed that these carbon materials promote DIET. The conductivity of biochar and GAC are approximately $2-5$ and $3000 \mathrm{uS} / \mathrm{cm}$, respectively, which suggests their potential to mediate electron exchange for DIET [12,14]. Liu et al. [14] observed significantly accelerated metabolic rates in the co-culture of G. metallireducens and G. sulfurreducens for ethanol oxidation when GAC was added. In addition, when GAC was added, the co-culture with G. sulfurreducens, in which the cytochrome OmcS was eliminated, could metabolize ethanol with reduction of fumarate. This was a different result from that of a previous study, which reported that the deletion of the genes encoding OmcS prevented any visible growth in the absence of conductive materials [8]. The authors explained that DIET in the presence of GAC does not require pili and c-type cytochrome to form a biological electrical connection. Similarly, the co-culture of G. metallireducens and M. barkeri showed much faster rates of ethanol-to-methane metabolism and SEM images revealed that microbial cells were tightly attached to the surface of the GAC without forming an aggregation between them. Chen et al. [12] provided experimental evidence that biochar promoted DIET between G. metallireducens and G. sulfurreducens or M. barkeri in a similar pathway as shared in a previous report. This suggests that biochar can also trigger DIET, although its conductivity is 1000 times lower than that of GAC.

The application of biochar and activated carbon in engineered systems has been studied under various conditions. Zhao et al. [65] compared the biomethanation performance of acetate and ethanol in an up-flow anaerobic sludge blanket reactor (UASB) when three different conductive carbon materials-biochar, graphite, and carbon cloth-were added. It was found that all of them promoted faster methane production with higher organic removal efficiency compared to the control without the addition of an amendment material. The sludge attached to the surfaces of each material accounted for less than $5 \%$ of the total sludge, which discounted the possibility of microbial attachment as the major reason for enhanced performance, given that the percentage improvement in methane production was $30-45 \%$. In addition, they reconfirmed this effect by removing all conductive materials from the UASB while keeping the biomass attached to the materials inside the reactor by carefully scraping off the biofilm layer with a knife. A decline was observed in the process performance in comparison with the original state. This result supported the fact that the major reason for the improved performance was the conductivity of the material and not the biomass retention. Zhao et al. [66] reported the enhancement in methane production (16-25\% increase compared to the control) from propionate and butyrate in the UASB with biochar amendment. A significant enrichment of Geobacter and Methanosaeta species compared to the control reactor suggested that the degradation of the organic acid was promoted by the biochar-mediated DIET. Lee et al. [13] demonstrated the applicability of GAC to facilitate DIET-mediated methanogenesis in continuous mode and this improvement was associated with the enrichment of primarily exoelectrogens and hydrogenotrophic methanogens in biomass attached to the GAC. Very few studies have demonstrated the effect of GAC addition on complex wastes instead of on artificial mono-substrates, including the use of commercial dog food as a substitute for dry organic fraction of municipal solid waste (OFMSW) and waste activated sludge (WAS) [67-69]. All of them observed that accelerated digestion rate and growth of putative DIET participants were stimulated; therefore, all proposed that conductive GAC can be used as an effective electron transfer mediator even in real wastewater streams.

Although biochar and activated carbon have recently received attention because of their ability to promote DIET, the effect of attached growth or microorganisms and the absorption of soluble compounds cannot be ignored. Activated carbon has been studied as an attractive additive for anaerobic digesters because its conductivity facilitates DIET between syntrophic microorganisms and because of its inherent absorption capacity. Xu et al. [70] compared the additive effect of activated carbon on the extent of enhancement in methanogenesis due to GAC and powdered activated carbon (PAC), which have different particle sizes. Both materials could facilitate syntrophic metabolism of the degradation of alcohols and fatty acids to methane, but PAC showed better performance with 
enrichment of syntrophs in the tightly bound fractions on its surface. This is because of its highly porous structure, which allows microorganisms to colonize inside it.

\subsection{Carbon Fibers}

Carbon cloth and felt are commonly used electrode materials in bioelectrochemical systems owing to their conductive characteristics. Carbon fibers have regular hexagonal rings aligned parallel to the long axis of the fibers, so that they show strong chemical and physical properties. Similar to biochar and activated carbon, carbon fibers have been used as a supporting medium for bacterial growth in bioreactors. Biofilms can easily form on the surfaces of carbon fibers and help in increasing biomass retention time inside the reactors, resulting in improved AD performance [71,72]. However, recent studies have suggested the possibility of using carbon fibers as DIET promoters.

Chen et al. [11] successfully confirmed the accelerating effect on DIET metabolism of carbon cloth addition in co-cultures of G. metallireducens with G. sulfurreducens or M. barkeri. The DIET metabolism between these species was not stimulated in co-cultures with poorly conductive cotton cloth, indicating that the electrically conductive characteristic of the carbon cloth is the major reason for the enhancement in metabolism. Meanwhile, the addition of carbon cloth is not effective in co-cultures between Desulfovibrio species (which make syntrophic relationships using hydrogen or formate as the electron carriers, but cannot be involved in DIET) and G. sulfurreducens, re-confirming the fact that the carbon cloth stimulated syntrophic metabolism by facilitating DIET.

Recently, carbon cloth $[65,67,68]$ and carbon felt $[67,73]$ have been used as conductive materials to facilitate DIET in mixed-culture environments. A recent study has reported that carbon cloth has a beneficial effect on the inhibiting condition caused by the acidic impact and high hydrogen partial pressure in anaerobic digesters [74]. The authors proposed that the dominating electron transfer mechanisms might be shifted toward DIET from IHT in the presence of carbon cloth in a harsh environment such as acidic $\mathrm{pH}$. It is in line with the phenomenon observed in anaerobic digesters, which became sour owing to imbalanced syntrophic mechanisms and then recovered rapidly after magnetite supplementation [6].

\subsection{Other Conductive Materials}

Graphene has been known to negatively affect the growth of microorganisms owing to its antimicrobial properties [75]; however, little research has considered its effect under anaerobic environments. Lin et al. [76] mentioned the potential of graphene as a solution for improved AD performance given that it has unique physicochemical properties such as extremely high electrical conductivity, large surface area, and great mechanical strength. Tian et al. [77] added nano-sized graphene with concentrations of 30 and $120 \mathrm{mg} / \mathrm{L}$ to the reactor, and observed significant increase in methane production rates (17.0\% and $51.4 \%$, respectively) from artificial wastewater with glucose as the carbon source. The activity of $\mathrm{F}_{420}$, a major coenzyme in the methanogenesis process, was remarkably increased (1.82-2.09 times) in the graphene-added reactor compared to the control. Lin et al. [76] reported that $1 \mathrm{~g} / \mathrm{L}$ of graphene is the optimal concentration for improving the methane production rate and yield from ethanol. Given that $20 \mathrm{~g} / \mathrm{L}$ of activated carbon should be added to obtain an enhancement in biomethane production, a much smaller amount of graphene is needed for DIET stimulation. This is probably due to the higher conductivity and larger specific surface area of graphene as compared to activated carbon.

Carbon nanotubes had been reported to be toxic to microorganisms because of the cytotoxic mechanism [78]. However, recently, several studies revealed that carbon nanotubes successfully promoted methanogenesis in syntrophic co-cultures as well as in complex environmental matrices [79,80]. Li et al. [79] explained how the cytotoxicity of carbon nanotubes could be reduced in experiments: in anaerobic condition, the oxidative stress by free radicals is less than in an aerobic environment, and the high-purity ( $>90 \%$ pure) carbon nanotubes used in this study might not induce any significant residual metal toxicity. Despite the potential of graphene and carbon nanotubes as 
DIET promoters, their application to field-scale processes might be difficult owing to their much higher cost than other conductive materials. The approximate estimated cost for addition of $1 \mathrm{~g} \mathrm{CNT/L}$ was $\$ 100,000 / \mathrm{m}^{3}$ of the digester, which is much higher than the cost for the addition of $50 \mathrm{~g} \mathrm{GAC} / \mathrm{L}$ $\left(\$ 15-150 / \mathrm{m}^{3}\right)[81]$.

\section{Perspectives}

Microorganisms involved in DIET are electrically connected to each other through cellular apparatuses, such as membrane-associated cytochromes and conductive pili, which enable the direct exchange of electrons without redox mediators. Recently, after the first observation of DIET in methanogenic cultures, an increasing number of studies have been made to understand the role of DIET in anaerobic environments. It has been demonstrated that conductive materials can act as a substitute for biological conductive structures and promote the DIET between VFA-degraders and methanogens in AD systems. This can eventually lead to the enhancement of AD performance given that DIET is energetically more efficient compared to IIET. This review discusses the significance of IET in syntrophic interactions in AD processes, the differences between IIET and DIET, and the potential of promoting DIET for enhanced methanogenesis. Recent studies on conductive material-promoted DIET and its influence on the methanogenic performance in different cultures are summarized. DIET is an interesting phenomenon, which seems to provide a unique opportunity to improve the AD processes at more fundamental levels. However, our knowledge of the role and potential of DIET in complex $\mathrm{AD}$ environments is rather limited, and more efforts are needed particularly to investigate engineered systems. The below-mentioned aspects may need to be examined and discussed in future studies.

- Different physicochemical characteristics of conductive materials: the conductive materials introduced in this review have different characteristics except for the fact that they all have sufficient conductivity for DIET stimulation. For example, activated carbon and biochar have higher porosity than the other materials. Carbon fiber has a large surface area because of its entangled structure; therefore, it provides higher surface area for microbial attachment as well as adsorption. Magnetite is a paramagnetic iron oxide particle that is strongly attracted to magnetic force, which suggests easier separation from mixed liquor. Such unique characteristics of different conductive materials can introduce additional effects during their application to engineered processes.

- Economic feasibility of DIET promotion: when conductive materials are used to promote the DIET mechanism, one possible way to reduce cost is minimizing the consumption of materials. As most field-scale anaerobic digesters operate in a continuous mode, it is important to prevent conductive materials from being washed out of reactors. Several experiments were conducted in up-flow type reactors, and a material that has enough density to settle down can be maintained inside the reactor without getting washed-out. Sequencing batch reactors can also be used to minimize the loss of material. In addition, as introduced in this review, magnetite can be separated from effluent by magnetic force and recycled. Further study is required into methods for minimizing the consumption and loss of each material while maintaining a desired level of performance.

- Ecophysiology of electrotrophic methanogens: there is lack of knowledge about the electrotrophic methanogens compared to their syntrophic partner, the exoelectrogens. Only a few species (i.e., Methanosarcina barkeri and Methanosaeta harundinaceae) have been experimentally proven as being capable of participating in DIET in defined co-cultures. Although there are several species that putatively accept electrons directly from others, only indirect evidence is presented in most studies (e.g., increase in the relative abundance of DIET-mediated conditions). Further studies on whether the potential electrotrophic methanogens can be involved in DIET and the detailed biological mechanisms of how they can accept electrons directly are needed. The outcomes from such research would also provide valuable information on electromethanogenesis systems, which are modified microbial electrolysis systems, whose cathodic activity for converting $\mathrm{CO}_{2}$ into $\mathrm{CH}_{4}$ relies heavily on electron transfer between the electrode and attached methanogens. 
- Combination with electrochemical systems: several recent studies revealed that voltage application on anaerobic digesters enhanced the organic degradation and methane production efficiencies. In this AD-microbial electrolysis cell (MEC) combined system, the exoelectrogens oxidize organic matter and release electrons to the anode, and the electrotrophic methanogens capture the electrons from the cathode to produce methane. This is a biocatalytic process in which microorganisms specialized for extracellular electron transport mechanisms participate. Further research is needed to determine whether or not there is a synergistic effect on the AD-MEC combined system when conductive materials are supplemented as DIET promoters.

Acknowledgments: This research was supported by the Korea Institute of Energy Technology Evaluation and Planning (KETEP) through the 'Human Resources Program in Energy Technology' (Grant No. 20164030201010) funded by the Ministry of Trade, Industry and Energy, and also by the Basic Science Research Program through the National Research Foundation of Korea (NRF) funded by the Ministry of Education (Grant No. 2017R1D1A1B03035489).

Author Contributions: Gahyun Baek, Jaai Kim, and Jinsu Kim designed and performed the literature review. Gahyun Baek and Changsoo Lee wrote the paper. Changsoo Lee supervised the preparation of the manuscript. All authors have approved the final manuscript.

Conflicts of Interest: The authors declare no conflict of interest.

\section{References}

1. Oller, I.; Malato, S.; Sánchez-Pérez, J. Combination of advanced oxidation processes and biological treatments for wastewater decontamination-A review. Sci. Total Environ. 2011, 409, 4141-4166. [CrossRef] [PubMed]

2. Angelidaki, I.; Ellegaard, L.; Ahring, B.K. Applications of the anaerobic digestion process. In Biomethanation II; Springer: Berlin, Germany, 2003; pp. 1-33.

3. Appels, L.; Lauwers, J.; Degrève, J.; Helsen, L.; Lievens, B.; Willems, K.; Van Impe, J.; Dewil, R. Anaerobic digestion in global bio-energy production: Potential and research challenges. Renew. Sustain. Energy Rev. 2011, 15, 4295-4301. [CrossRef]

4. Kim, J.; Lim, J.; Lee, C. Quantitative real-time PCR approaches for microbial community studies in wastewater treatment systems: Applications and considerations. Biotechnol. Adv. 2013, 31, 1358-1373. [CrossRef] [PubMed]

5. Batstone, D.; Picioreanu, C.; Van Loosdrecht, M. Multidimensional modelling to investigate interspecies hydrogen transfer in anaerobic biofilms. Water Res. 2006, 40, 3099-3108. [CrossRef] [PubMed]

6. Baek, G.; Kim, J.; Lee, C. A long-term study on the effect of magnetite supplementation in continuous anaerobic digestion of dairy effluent-Enhancement in process performance and stability. Bioresour. Technol. 2016, 222, 344-354. [CrossRef] [PubMed]

7. Lovley, D.R. Live wires: Direct extracellular electron exchange for bioenergy and the bioremediation of energy-related contamination. Energy Environ. Sci. 2011, 4, 4896-4906. [CrossRef]

8. Summers, Z.M.; Fogarty, H.E.; Leang, C.; Franks, A.E.; Malvankar, N.S.; Lovley, D.R. Direct exchange of electrons within aggregates of an evolved syntrophic coculture of anaerobic bacteria. Science 2010, 330, 1413-1415. [CrossRef] [PubMed]

9. Rotaru, A.-E.; Shrestha, P.M.; Liu, F.; Ueki, T.; Nevin, K.; Summers, Z.M.; Lovley, D.R. Interspecies electron transfer via hydrogen and formate rather than direct electrical connections in cocultures of Pelobacter carbinolicus and Geobacter sulfurreducens. Appl. Environ. Microbiol. 2012, 78, 7645-7651. [CrossRef] [PubMed]

10. Kato, S.; Hashimoto, K.; Watanabe, K. Methanogenesis facilitated by electric syntrophy via (semi) conductive iron-oxide minerals. Environ. Microbiol. 2012, 14, 1646-1654. [CrossRef] [PubMed]

11. Chen, S.; Rotaru, A.-E.; Liu, F.; Philips, J.; Woodard, T.L.; Nevin, K.P.; Lovley, D.R. Carbon cloth stimulates direct interspecies electron transfer in syntrophic co-cultures. Bioresour. Technol. 2014, 173, 82-86. [CrossRef] [PubMed]

12. Chen, S.; Rotaru, A.-E.; Shrestha, P.M.; Malvankar, N.S.; Liu, F.; Fan, W.; Nevin, K.P.; Lovley, D.R. Promoting interspecies electron transfer with biochar. Sci. Rep. 2014, 4, 5019. [CrossRef] [PubMed]

13. Lee, J.-Y.; Lee, S.-H.; Park, H.-D. Enrichment of specific electro-active microorganisms and enhancement of methane production by adding granular activated carbon in anaerobic reactors. Bioresour. Technol. 2016, 205, 205-212. [CrossRef] [PubMed] 
14. Liu, F.; Rotaru, A.-E.; Shrestha, P.M.; Malvankar, N.S.; Nevin, K.P.; Lovley, D.R. Promoting direct interspecies electron transfer with activated carbon. Energy Environ. Sci. 2012, 5, 8982-8989. [CrossRef]

15. Lovley, D.R. Powering microbes with electricity: Direct electron transfer from electrodes to microbes. Environ. Microbiol. Rep. 2011, 3, 27-35. [CrossRef] [PubMed]

16. Lovley, D.R. Reach out and touch someone: Potential impact of DIET (direct interspecies energy transfer) on anaerobic biogeochemistry, bioremediation, and bioenergy. Rev. Environ. Sci. Bio/Technol. 2011, 10, 101-105. [CrossRef]

17. Shrestha, P.M.; Rotaru, A.-E. Plugging in or going wireless: Strategies for interspecies electron transfer. Front. Microbiol. 2015, 142, 237. [CrossRef] [PubMed]

18. Stams, A.J.; Plugge, C.M. Electron transfer in syntrophic communities of anaerobic bacteria and archaea. Nat. Rev. Microbiol. 2009, 7, 568-577. [CrossRef] [PubMed]

19. Kaparaju, P.; Buendia, I.; Ellegaard, L.; Angelidakia, I. Effects of mixing on methane production during thermophilic anaerobic digestion of manure: Lab-scale and pilot-scale studies. Bioresour. Technol. 2008, 99, 4919-4928. [CrossRef] [PubMed]

20. Kim, M.; Ahn, Y.-H.; Speece, R. Comparative process stability and efficiency of anaerobic digestion; mesophilic vs. thermophilic. Water Res. 2002, 36, 4369-4385. [CrossRef]

21. Stams, A.J. Metabolic interactions between anaerobic bacteria in methanogenic environments. Antonie van Leeuwenhoek 1994, 66, 271-294. [CrossRef] [PubMed]

22. Thiele, J.H.; Zeikus, J.G. Control of interspecies electron flow during anaerobic digestion: Significance of formate transfer versus hydrogen transfer during syntrophic methanogenesis in flocs. Appl. Environ. Microbiol. 1988, 54, 20-29. [PubMed]

23. Bélaich, J.-P.; Bruschi, M.; Garcia, J.-L. Microbiology and Biochemistry of Strict Anaerobes Involved in Interspecies Hydrogen Transfer; Springer Science \& Business Media: Berlin, Germany, 2012.

24. Lovley, D.R.; Goodwin, S. Hydrogen concentrations as an indicator of the predominant terminal electron-accepting reactions in aquatic sediments. Geochim. Cosmochim. Acta 1988, 52, 2993-3003. [CrossRef]

25. Casalot, L.; Rousset, M. Maturation of the [NiFe] hydrogenases. Trends Microbiol. 2001, 9, 228-237. [CrossRef]

26. Stams, A.J.; De Bok, F.A.; Plugge, C.M.; Eekert, V.; Miriam, H.; Dolfing, J.; Schraa, G. Exocellular electron transfer in anaerobic microbial communities. Environ. Microbiol. 2006, 8, 371-382. [CrossRef] [PubMed]

27. Schink, B. Energetics of syntrophic cooperation in methanogenic degradation. Microbiol. Mol. Biol. Rev. 1997, 61, 262-280. [PubMed]

28. Kim, B.H.; Gadd, G.M. Bacterial Physiology and Metabolism; Cambridge University Press: Cambridge, UK, 2008.

29. Liu, Y.; Whitman, W.B. Metabolic, phylogenetic, and ecological diversity of the methanogenic archaea. Ann. N. Y. Acad. Sci. 2008, 1125, 171-189. [CrossRef] [PubMed]

30. Boone, D.R.; Johnson, R.L.; Liu, Y. Diffusion of the interspecies electron carriers $\mathrm{H}_{2}$ and formate in methanogenic ecosystems and its implications in the measurement of $\mathrm{Km} \mathrm{for} \mathrm{H}_{2}$ or formate uptake. Appl. Environ. Microbiol. 1989, 55, 1735-1741. [PubMed]

31. De Bok, F.; Plugge, C.; Stams, A. Interspecies electron transfer in methanogenic propionate degrading consortia. Water Res. 2004, 38, 1368-1375. [CrossRef] [PubMed]

32. Cheng, Q.; Call, D.F. Hardwiring microbes via direct interspecies electron transfer: Mechanisms and applications. Environ. Sci. Processes Impacts 2016, 18, 968-980. [CrossRef] [PubMed]

33. Kato, S.; Watanabe, K. Ecological and evolutionary interactions in syntrophic methanogenic consortia. Microbes Environ. 2010, 25, 145-151. [CrossRef] [PubMed]

34. Arbeli, Z.; Brenner, A.; Abeliovich, A. Treatment of high-strength dairy wastewater in an anaerobic deep reservoir: Analysis of the methanogenic fermentation pathway and the rate-limiting step. Water Res. 2006, 40, 3653-3659. [CrossRef] [PubMed]

35. Jing, Y.; Wan, J.; Angelidaki, I.; Zhang, S.; Luo, G. iTRAQ quantitative proteomic analysis reveals the pathways for methanation of propionate facilitated by magnetite. Water Res. 2017, 108, 212-221. [CrossRef] [PubMed]

36. Storck, T.; Virdis, B.; Batstone, D.J. Modelling extracellular limitations for mediated versus direct interspecies electron transfer. ISME J. 2016, 10, 621-631. [CrossRef] [PubMed]

37. Leang, C.; Qian, X.; Mester, T.; Lovley, D.R. Alignment of the c-type cytochrome OmcS along pili of Geobacter sulfurreducens. Appl. Environ. Microbiol. 2010, 76, 4080-4084. [CrossRef] [PubMed] 
38. Rotaru, A.-E.; Shrestha, P.M.; Liu, F.; Shrestha, M.; Shrestha, D.; Embree, M.; Zengler, K.; Wardman, C.; Nevin, K.P.; Lovley, D.R. A new model for electron flow during anaerobic digestion: Direct interspecies electron transfer to Methanosaeta for the reduction of carbon dioxide to methane. Energy Environ. Sci. 2014, 7, 408-415. [CrossRef]

39. Shi, L.; Squier, T.C.; Zachara, J.M.; Fredrickson, J.K. Respiration of metal (hydr) oxides by Shewanella and Geobacter: A key role for multihaem c-type cytochromes. Mol. Microbiol. 2007, 65, 12-20. [CrossRef] [PubMed]

40. Eaktasang, N.; Kang, C.S.; Lim, H.; Kwean, O.S.; Cho, S.; Kim, Y.; Kim, H.S. Production of electrically-conductive nanoscale filaments by sulfate-reducing bacteria in the microbial fuel cell. Bioresour. Technol. 2016, 210, 61-67. [CrossRef] [PubMed]

41. Gorby, Y.A.; Yanina, S.; McLean, J.S.; Rosso, K.M.; Moyles, D.; Dohnalkova, A.; Beveridge, T.J.; Chang, I.S.; Kim, B.H.; Kim, K.S. Electrically conductive bacterial nanowires produced by Shewanella oneidensis strain MR-1 and other microorganisms. Proc. Natl. Acad. Sci. USA 2006, 103, 11358-11363. [CrossRef] [PubMed]

42. Malvankar, N.S.; Tuominen, M.T.; Lovley, D.R. Lack of cytochrome involvement in long-range electron transport through conductive biofilms and nanowires of Geobacter sulfurreducens. Energy Environ. Sci. 2012, 5, 8651-8659. [CrossRef]

43. Malvankar, N.S.; Lovley, D.R. Microbial nanowires: A new paradigm for biological electron transfer and bioelectronics. ChemSusChem 2012, 5, 1039-1046. [CrossRef] [PubMed]

44. Holmes, D.E.; Dang, Y.; Walker, D.J.; Lovley, D.R. The electrically conductive pili of Geobacter species are a recently evolved feature for extracellular electron transfer. Microb. Genom. 2016, 2, e000072. [CrossRef] [PubMed]

45. Malvankar, N.S.; Vargas, M.; Nevin, K.P.; Franks, A.E.; Leang, C.; Kim, B.-C.; Inoue, K.; Mester, T.; Covalla, S.F.; Johnson, J.P. Tunable metallic-like conductivity in microbial nanowire networks. Nat. Nanotechnol. 2011, 6, 573-579. [CrossRef] [PubMed]

46. Pirbadian, S.; Barchinger, S.E.; Leung, K.M.; Byun, H.S.; Jangir, Y.; Bouhenni, R.A.; Reed, S.B.; Romine, M.F.; Saffarini, D.A.; Shi, L. Shewanella oneidensis MR-1 nanowires are outer membrane and periplasmic extensions of the extracellular electron transport components. Proc. Natl. Acad. Sci. USA 2014, 111, 12883-12888. [CrossRef] [PubMed]

47. Rotaru, A.-E.; Shrestha, P.M.; Liu, F.; Markovaite, B.; Chen, S.; Nevin, K.P.; Lovley, D.R. Direct interspecies electron transfer between Geobacter metallireducens and Methanosarcina barkeri. Appl. Environ. Microbiol. 2014, 80, 4599-4605. [CrossRef] [PubMed]

48. Moon, J.W.; Roh, Y.; Lauf, R.J.; Vali, H.; Yeary, L.W.; Phelps, T.J. Microbial preparation of metal-substituted magnetite nanoparticles. J. Microbiol. Methods 2007, 70, 150-158. [CrossRef] [PubMed]

49. Nidheesh, P. Heterogeneous Fenton catalysts for the abatement of organic pollutants from aqueous solution: A review. RSC Adv. 2015, 5, 40552-40577. [CrossRef]

50. Sun, S.; Zeng, H. Size-controlled synthesis of magnetite nanoparticles. J. Am. Chem. Soc. 2002, 124, 8204-8205. [CrossRef] [PubMed]

51. Guskos, N.; Papadopoulos, G.; Likodimos, V.; Patapis, S.; Yarmis, D.; Przepiera, A.; Przepiera, K.; Majszczyk, J.; Typek, J.; Wabia, M.; et al. Photoacoustic, EPR and electrical conductivity investigations of three synthetic mineral pigments: Hematite, goethite and magnetite. Mater. Res. Bull. 2002, 37, 1051-1061. [CrossRef]

52. Kato, S.; Hashimoto, K.; Watanabe, K. Microbial interspecies electron transfer via electric currents through conductive minerals. Proc. Natl. Acad. Sci. USA 2012, 109, 10042-10046. [CrossRef] [PubMed]

53. Cruz Viggi, C.; Rossetti, S.; Fazi, S.; Paiano, P.; Majone, M.; Aulenta, F. Magnetite particles triggering a faster and more robust syntrophic pathway of methanogenic propionate degradation. Environ. Sci. Technol. 2014, 48, 7536-7543. [CrossRef] [PubMed]

54. Li, H.; Chang, J.; Liu, P.; Fu, L.; Ding, D.; Lu, Y. Direct interspecies electron transfer accelerates syntrophic oxidation of butyrate in paddy soil enrichments. Environ. Microbiol. 2015, 17, 1533-1547. [CrossRef] [PubMed]

55. Yamada, C.; Kato, S.; Ueno, Y.; Ishii, M.; Igarashi, Y. Conductive iron oxides accelerate thermophilic methanogenesis from acetate and propionate. J. Biosci. Bioeng. 2015, 119, 678-682. [CrossRef] [PubMed]

56. Yang, Z.; Guo, R.; Shi, X.; Wang, C.; Wang, L.; Dai, M. Magnetite nanoparticles enable a rapid conversion of volatile fatty acids to methane. RSC Adv. 2016, 6, 25662-25668. [CrossRef] 
57. Zhuang, L.; Tang, J.; Wang, Y.; Hu, M.; Zhou, S. Conductive iron oxide minerals accelerate syntrophic cooperation in methanogenic benzoate degradation. J. Hazard. Mater. 2015, 293, 37-45. [CrossRef] [PubMed]

58. Baek, G.; Kim, J.; Cho, K.; Bae, H.; Lee, C. The biostimulation of anaerobic digestion with (semi) conductive ferric oxides: Their potential for enhanced biomethanation. Appl. Microbiol. Biotechnol. 2015, 99, 10355-10366. [CrossRef] [PubMed]

59. Baek, G.; Jung, H.; Kim, J.; Lee, C. A long-term study on the effect of magnetite supplementation in continuous anaerobic digestion of dairy effluent-Magnetic separation and recycling of magnetite. Bioresour. Technol. 2017, 241, 830-840. [CrossRef] [PubMed]

60. Mumme, J.; Srocke, F.; Heeg, K.; Werner, M. Use of biochars in anaerobic digestion. Bioresour. Technol. 2014, 164, 189-197. [CrossRef] [PubMed]

61. Thies, J.E.; Rillig, M.C. Characteristics of biochar: Biological properties. In Biochar for Environmental Management: Science and Technology; Earthscan: London, UK, 2009; Chapter 6, pp. 85-105.

62. Luo, C.; Lü, F.; Shao, L.; He, P. Application of eco-compatible biochar in anaerobic digestion to relieve acid stress and promote the selective colonization of functional microbes. Water Res. 2015, 68, 710-718. [CrossRef] [PubMed]

63. Azargohar, R.; Dalai, A. Biochar as a precursor of activated carbon. In Twenty-Seventh Symposium on Biotechnology for Fuels and Chemicals; Springer: Berlin, Germany, 2006; pp. 762-773.

64. Hansen, K.H.; Angelidaki, I.; Ahring, B.K. Improving thermophilic anaerobic digestion of swine manure. Water Res. 1999, 33, 1805-1810. [CrossRef]

65. Zhao, Z.; Zhang, Y.; Woodard, T.; Nevin, K.; Lovley, D. Enhancing syntrophic metabolism in up-flow anaerobic sludge blanket reactors with conductive carbon materials. Bioresour. Technol. 2015, 191, 140-145. [CrossRef] [PubMed]

66. Zhao, Z.; Zhang, Y.; Holmes, D.E.; Dang, Y.; Woodard, T.L.; Nevin, K.P.; Lovley, D.R. Potential enhancement of direct interspecies electron transfer for syntrophic metabolism of propionate and butyrate with biochar in up-flow anaerobic sludge blanket reactors. Bioresour. Technol. 2016, 209, 148-156. [CrossRef] [PubMed]

67. Dang, Y.; Holmes, D.E.; Zhao, Z.; Woodard, T.L.; Zhang, Y.; Sun, D.; Wang, L.-Y.; Nevin, K.P.; Lovley, D.R. Enhancing anaerobic digestion of complex organic waste with carbon-based conductive materials. Bioresour. Technol. 2016, 220, 516-522. [CrossRef] [PubMed]

68. Dang, Y.; Sun, D.; Woodard, T.L.; Wang, L.-Y.; Nevin, K.P.; Holmes, D.E. Stimulation of the anaerobic digestion of the dry organic fraction of municipal solid waste (OFMSW) with carbon-based conductive materials. Bioresour. Technol. 2017, 238, 30-38. [CrossRef] [PubMed]

69. Yang, Y.; Zhang, Y.; Li, Z.; Zhao, Z.; Quan, X.; Zhao, Z. Adding granular activated carbon into anaerobic sludge digestion to promote methane production and sludge decomposition. J. Clean. Prod. 2017, 149, 1101-1108. [CrossRef]

70. Xu, S.; He, C.; Luo, L.; Lü, F.; He, P.; Cui, L. Comparing activated carbon of different particle sizes on enhancing methane generation in upflow anaerobic digester. Bioresour. Technol. 2015, 196, 606-612. [CrossRef] [PubMed]

71. Tatara, M.; Makiuchi, T.; Ueno, Y.; Goto, M.; Sode, K. Methanogenesis from acetate and propionate by thermophilic down-flow anaerobic packed-bed reactor. Bioresour. Technol. 2008, 99, 4786-4795. [CrossRef] [PubMed]

72. Zhang, D.; Zhu, W.; Tang, C.; Suo, Y.; Gao, L.; Yuan, X.; Wang, X.; Cui, Z. Bioreactor performance and methanogenic population dynamics in a low-temperature $\left(5-18{ }^{\circ} \mathrm{C}\right)$ anaerobic fixed-bed reactor. Bioresour. Technol. 2012, 104, 136-143. [CrossRef] [PubMed]

73. Lei, Y.; Sun, D.; Dang, Y.; Chen, H.; Zhao, Z.; Zhang, Y.; Holmes, D.E. Stimulation of methanogenesis in anaerobic digesters treating leachate from a municipal solid waste incineration plant with carbon cloth. Bioresour. Technol. 2016, 222, 270-276. [CrossRef] [PubMed]

74. Zhao, Z.; Zhang, Y.; Li, Y.; Dang, Y.; Zhu, T.; Quan, X. Potentially shifting from interspecies hydrogen transfer to direct interspecies electron transfer for syntrophic metabolism to resist acidic impact with conductive carbon cloth. Chem. Eng. J. 2017, 313, 10-18. [CrossRef]

75. Santos, C.M.; Mangadlao, J.; Ahmed, F.; Leon, A.; Advincula, R.C.; Rodrigues, D.F. Graphene nanocomposite for biomedical applications: Fabrication, antimicrobial and cytotoxic investigations. Nanotechnology 2012, 23, 395101. [CrossRef] [PubMed] 
76. Lin, R.; Cheng, J.; Zhang, J.; Zhou, J.; Cen, K.; Murphy, J.D. Boosting biomethane yield and production rate with graphene: The potential of direct interspecies electron transfer in anaerobic digestion. Bioresour. Technol. 2017, 239, 345-352. [CrossRef] [PubMed]

77. Tian, T.; Qiao, S.; Li, X.; Zhang, M.; Zhou, J. Nano-graphene induced positive effects on methanogenesis in anaerobic digestion. Bioresour. Technol. 2017, 224, 41-47. [CrossRef] [PubMed]

78. Simon-Deckers, A.; Loo, S.; Mayne-L'hermite, M.; Herlin-Boime, N.; Menguy, N.; Reynaud, C.; Gouget, B.; Carriere, M. Size-, composition-and shape-dependent toxicological impact of metal oxide nanoparticles and carbon nanotubes toward bacteria. Environ. Sci. Technol. 2009, 43, 8423-8429. [CrossRef] [PubMed]

79. Li, L.-L.; Tong, Z.-H.; Fang, C.-Y.; Chu, J.; Yu, H.-Q. Response of anaerobic granular sludge to single-wall carbon nanotube exposure. Water Res. 2015, 70, 1-8. [CrossRef] [PubMed]

80. Salvador, A.F.; Martins, G.; Melle-Franco, M.; Serpa, R.; Stams, A.J.; Cavaleiro, A.J.; Pereira, M.A.; Alves, M.M. Carbon nanotubes accelerate methane production in pure cultures of methanogens and in a syntrophic coculture. Environ. Microbiol. 2017, 19, 2727-2739. [CrossRef] [PubMed]

81. Barua, S.; Dhar, B.R. Advances towards understanding and engineering direct interspecies electron transfer in anaerobic digestion. Bioresour. Technol. 2017, 244, 698-707. [CrossRef] [PubMed]

(C) 2018 by the authors. Licensee MDPI, Basel, Switzerland. This article is an open access article distributed under the terms and conditions of the Creative Commons Attribution (CC BY) license (http:/ / creativecommons.org/licenses/by/4.0/). 